\title{
Legal regulation of mental healthcare provision in Russia
}

\author{
N. G. Neznanov ${ }^{1}$ and V. Vasileva ${ }^{2}$
}

${ }^{1}$ President, Russian Society of Psychiatrists; President, World Association for Dynamic Psychiatry (WADP); Director, St Petersburg V.M. Bekhterev Psychoneurological Research Institute, Russia; Chief Specialist Expert in Psychiatry of the Federal Service on Surveillance in Healthcare and Social in Healthcare and Social
Development of the Russian Development
Federation

2Leading Research Associate, Deputy Director, Department Deputy Director, Department of International Cooperation, St Petersburg V.M. Bekhterev Psychoneurological Research Institute, Russia, email annavdoc@yahoo.com
The article describes the changes that have taken place in the mental healthcare system in Russia since a new mental health law came into force. The focus is on involuntary hospitalisation and the guarantee of patients' rights.

In Russia, reforms to the mental healthcare system took place during the last decade of the 20th century, against a background of great social and economic change. Not only in psychiatry but throughout medicine, those reforms brought in democratisation, the principle of informed consent and a shift from a paternalistic to a partnership paradigm in healthcare. However, the same period saw the introduction of private mental health services and a system in which many psychiatric patients do not get adequate treatment. The reforms also had an impact on the continuity of care between in-patient and out-patient services. Regrettably, new legislation prohibited the use of placebo treatments, which had proved to be highly effective, for example with conversion disorders.

The legal regulation of mental healthcare and psychiatric care in the Russian Federation is principally through the Law on Mental Healthcare and Guarantees of the Citizens' Rights in the Course of Care Provision, although there are other federal laws and other provisions regulating government, federal agencies and citizens. That Law was developed in accordance with the principles recommended by the United Nations; it came into force on 1 January 1993. The Preamble states that mental health is of fundamental importance to every person. It underscores that a lack of specific legal regulation of mental healthcare can allow such 'care' to be used for non-medical purposes and can damage the person's health, dignity and rights, as well as the state's international reputation.

\section{Diagnosis}

Mental disorder is defined in line with ICD-10 (sections F00-F99) (World Health Organization, 1992). Only psychiatrists are permitted to diagnose mental disorder. Statements of medical doctors of other specialties are considered only preliminary. Non-medical professionals do not have the right to determine the presence of mental disorder. The law emphasises that admission to a mental institution should be used only for the purposes of treatment.

\section{Consent}

Treatment should generally be given with the patient's informed consent, defined as 'voluntary, competent permission of the patient to receive therapy', after receiving full and objective information about the procedure, its possible complications and any alternatives. If patients are unable to give informed consent, another person is generally authorised to give consent on their behalf (e.g. parents or legal guardians).

\section{Involuntary hospitalisation}

The criteria for involuntary hospitalisation are:

- the person exhibits dangerous behaviour to himself or herself, or others

- the person is helpless and cannot provide for his or her basic daily needs

- there is a danger of 'essential harm' to the mental health of the person if she or he is not in receipt of mental care.

The decision is made by a psychiatrist, who should document a detailed description of the person's mental condition. The necessary measures can be applied only by medical staff and should be thoroughly described and justified in special medical records. In the admission room the psychiatrist in charge should evaluate the mental status of the patient and check that the criteria for involuntary admission still apply. In the case of disagreement, the psychiatrist of the admission unit has the right to discharge the patient from compulsory treatment.

During the next 48 hours a commission of psychiatrists evaluates the involuntary patient and determines whether further detention is justified. The patient has the right to invite any specialist (a psychiatrist or psychologist) to participate in this process. If it is decided the hospitalisation is unjustified the patient is immediately dismissed, even if there are indications for voluntary treatment.

Where the involuntary hospitalisation is deemed justified, the mental institution should in the next 24 hours send an application to the local court together with the commission's conclusion and all the relevant documentation. The court has 5 days to consider the application. The patient has the right to be present in court; if the patient's mental condition does not allow this, the court sitting should take place in the mental hospital, which gives the judge opportunity to meet the patient personally.

In the next 10 days, the patient or the patient's representative as well as the head of the mental institution, or the organisation authorised to protect the rights of patients, have the right to appeal against the judge's decision to approve or decline the application for involuntary hospitalisation. 
During the first 6 months, the need for involuntary treatment of the patient should be re-evaluated every month by the commission of psychiatrists. Thereafter, the re-evaluation should be done at least every 6 months. After 6 months of involuntary hospitalisation the commission sends the local court its decision on the need for continued involuntary in-patient treatment. Any further prolongation of treatment is approved by a judge annually.

Patients have the right: to ask questions concerning diagnostic procedures, treatment and dismissal; to make appeals without censorship in court or by executive authorities; and to meet alone with a lawyer or a representative of the state law bureau, or members of the clergy. There is an independent service that defends in-patients' rights. It accepts patient complaints and either resolves them with the head of the medical institution or refers them to the relevant court or executive authority.

\section{Other forms of compulsory treatment}

Under the Criminal Code of the Russian Federation, compulsory treatment can be given to patients with a mental illness who commit socially dangerous acts. Whether the mental disorder demands such treatment, care and observation is a decision made by a court. Treatment will be in a mental hospital if compulsory out-patient treatment is not possible. It will be in a general mental hospital unless the patient's condition (e.g involving extreme danger for himself or herself and others) needs constant intensive surveillance and so requires admission to a special mental hospital. The court makes the decision on the basis of an expert psychiatric commission's conclusion and all the other evidence. The commission explains the recommended treatment on the principle of necessity and adequacy for the prevention of socially dangerous acts. Individual treatment and rehabilitation procedures are suggested. Members of the commission should have a licence in forensic psychiatry.

On the basis of an evaluation of mental status, the type of mental disorder and violation of the law, the court makes a decision about the specific compulsory treatment and chooses the type of mental hospital to which the person should be sent for treatment. During the course of treatment the psychiatric commission should re-evaluate the mental condition of the patient every 6 months, undertake a re-evaluation of the mental condition of the patient and make a decision about further treatment.

\section{Other legislative provisions}

According to the Federal Law on Fundamentals of Healthcare of the Citizens in the Russian Federation, medical institutions of the subjects (i.e. states) of the Russian Federation in the sphere of mental healthcare are responsible for the development and implementation of measures of social support and medical care for persons with socially significant diseases (including mental disorders), as well as the provision of medications for this category of persons.

Persons with socially significant diseases are entitled to medical care and regular medical check-ups at relevant medical facilities (dispensaries). Article 16 of the Law on Mental Healthcare and the Guarantees of the Citizens' Rights in the Course of Care Provision lists the following mental health services and social support measures guaranteed by the state:

- emergency mental healthcare

- consultation for diagnostic, treatment, psychopreventive and rehabilitation services at in- and out-patient facilities

- all types of psychiatric examination establishing temporary disability

- social support and employment assistance for people with mental disorders

- resolution of custody-related problems

- legal consultations and other types of legal aid at mental and psychoneurological facilities

- social care and nursing for disabled and elderly persons with mental disorders

- the education of disabled persons and minors with mental disorders

- psychiatric aid in cases of natural disasters and catastrophic events.

To provide mental healthcare and social support for persons with mental disorders, the state:

- establishes all types of mental healthcare inand out-patient facilities, located, if possible, close to the patient's place of residence

- arranges general and vocational education for minors with mental disorders.

The provision of mental healthcare is organised at both state and federal level: federal specialised medical facilities listed and approved by the government of the Russian Federation; and specialised medical facilities of the subjects of the Russian Federation.

\section{Conclusion}

We can say that legislative changes to the mental healthcare system have brought about the expansion of rights of persons suffering from mental disorders as well as new challenges for professionals dealing with lack of insight and non-compliance in their daily practice.

There remains much to be done to overcome prejudice against and stigmatisation (including self-stigmatisation) of psychiatric patients in society, and here legislative change can be only the first step on the long way to integration.

\section{Reference}

World Health Organization (1992) The ICD-10 Classification of Mental and Behavioural Disorders (10th revision) (ICD-10). WHO. 